\title{
O Voto Pró-Ditadura \\ : o eleitorado da Arena nas eleiçóes regionais no Estado do Rio Grande do Sul entre 1966 e 1974
}

\author{
André Luiz dos Santos Ramos Filho \\ Especializado em Sociedade, Política e Cultura pela FURG
}

\section{Resumo}

A Ditadura Civil-Militar é um dos temas mais abordados na historiografia nacional atualmente. Alguns de seus aspectos, no entanto, ainda merecem um olhar mais aprofundado. É o caso da dinâmica eleitoral durante a vigência do sistema bipartidário. No Estado do Rio Grande do Sul, as eleições para o Senado Federal substituíam, em termos de disputa, o pleito majoritário para o governo do estado, que fora suspenso com a imposição do Ato Institucional n.o 3. O partido do governo, a Aliança Renovadora Nacional (ARENA), atingiu resultados importantes nas urnas, elegendo seus candidatos nos pleitos de 1966 e 1970. Pretendemos analisar, no presente artigo, como se desenvolveu a campanha eleitoral arenista neste período, através da imprensa, e se os votos recebidos por esse partido se constituem como uma forma de apoio que a sociedade gaúcha emprestou à implantação de um regime de exceção.

Palavras-chave Ditadura, Bipartidarismo, ARENA, Eleições, Rio Grande do Sul.

\section{Abstract}

The Civil-Military Dictatorship is one of the topics discussed in Brazilian historiography today. Some of its aspects, however, still deserve a closer look. Is the case of electoral dynamics during the life of the twoparty system. In the state of Rio Grande do Sul, the elections to the Senate replaced in terms of dispute, the election for governor, who was suspended BY imposition of Institutional Act No. 3. The government party, the Aliança Renovadora Nacional (ARENA) reached important results in disputes, electing its candidates in the 1966 and 1970 elections. We intend to analyze, in this article, how it developed the Arena party election campaign in this period, through the press, and if the votes cast for that party are a form of support that the society lent to the implementation of an exception regime

Keywords Dictatorship, Bipartisanship, ARENA, Elections, Rio Grande do Sul. 


\section{Introdução}

Ditadura Civil Militar Brasileira é um dos temas mais abordados pela historiografia
nacional atualmente. Com a proximidade do cinquentenário de sua implantação, tal interesse aumenta significativamente. Embora muitos trabalhos já tenham se debruçado sobre os mais diversos elementos da conjuntura a partir de 1964, nota-se que alguns pontos são pouco explorados pelos autores.

Tal situação pode ser observada quando levamos em conta a questão eleitoral do período. Ainda que a dita "Revolução" tenha restringido direitos e limitado instituições, as eleições foram mantidas para alguns cargos, tornando-se um campo vasto para a análise do comportamento da população e como esta se manifestava diante das modificações introduzidas pelos militares. A partir de 1965 , com a remodelação do sistema políticopartidário e a imposição do bipartidarismo, os pleitos dotaram-se, cada vez mais, de um caráter plebiscitário.

O estado do Rio Grande do Sul não estava excluído deste contexto. Durante treze anos (1965-1978), as eleições eram o palco em que se enfrentavam os apoiadores do regime e os seus oposicionistas. Diante disso, o presente artigo tem como objetivo a análise dos votos recebidos pelo partido Aliança Renovadora Nacional - ARENA - e da campanha eleitoral durante a égide do bipartidarismo, entre os anos de 1966 e 1974, nas eleições regionais no Rio Grande do Sul, na disputa pelo cargo de Senador da República. Para tanto, utilizaremos os dados dos resultados das eleiçóes de 1966, 1970 e 1974, junto aos apontamentos da imprensa durante as respectivas campanhas, representados pelas matérias jornalísticas e as propagandas eleitorais veiculadas no jornal Correio do Povo, de Porto Alegre.

Alguns autores já abordaram o tema, como é o caso de Marcelo Baquero e Jussara Reis Prá ${ }^{\text {, Júlio Chiavenato }}{ }^{2}$, Daniel Aarão Reis Filho3 , Carla Rodeghero ${ }^{4}$, Hélgio Trindade e Maria Izabel Nolls (1995 e 2005), no entanto, o enfoque dado sempre foi a partir da oposição ao regime, isto é, da evolução dos votos recebidos pelo partido Movimento Democrático

I BAQUERO, Marcello; PRÁ, Jussara Reis. A democracia brasileira e a cultura politica no Rio Grande do Sul. Porto Alegre: UFRGS, 2007.

2 CHIAVENATO, Júlio José. O golpe de 64 e a ditadura militar. São Paulo: Moderna, 1994.

3 REIS FILHO, Daniel Aarão. Ditadura militar, esquerdas e sociedade. 3. ed. Rio de Janeiro: Zahar, 2005.

4 RODEGHERO, Carla Simone. Regime militar e oposição. In: BOEIRA, Nelson; GOLIN, Tau (Coord.) História Geral do Rio Grande do Sul. Passo Fundo: Méritos, 2007. 4v.

5 NOLL, Maria Izabel; TRINDADE, Hélgio. Estatisticas eleitorais do Rio Grande da América do Sul: 1823/2002. Porto Alegre: UFRGS, 2004. NOLL, Maria Izabel; e TRINDADE, Hélgio (Coord.) Estatísticas eleitorais comparativas do Rio Grande do Sul: 1945-1994. Porto Alegre: Ed. da Universidade / UFRGS, I995. 
RAMOS FILHO, André Luiz dos Santos (...) USP - Ano IX, n. I4, p. II7-I38, 2018 Brasileiro - MDB. Intencionamos analisar se os resultados das eleições, do período referido, podem demonstrar uma forma de apoio que grande parte da sociedade gaúcha prestou à instalação e manutenção de um regime de exceção. A perspectiva que será adotada é a da manutenção de padrões em resultados, e não de oscilações, como até então tem se focado a maioria das obras.

\section{Legitimação, bipartidarismo e a ARENA no Rio Grande do Sul}

Consumados os acontecimentos de abril de 1964, consolidando o sucesso do golpe, o novo regime passou a construir uma relação de legitimação para seus atos. Conforme nos afirmam Petersen e Biz:

Embora todos os Estados façam uso, em maior ou menor grau, da força e da violência, a relação comando/obediência não se constitui apenas numa resposta à ação do aparelho repressivo de Estado. É sabido que, concomitantemente com o uso do aparelho coercitivo, os diferentes regimes procuram desenvolver na sociedade civil uma atitude favorável em relação a suas políticas, ou seja, procuram construir a sua legitimação. ${ }^{6}$

Assim, não só da força se utilizaram os militares para impor o seu conjunto de ações ao longo do governo. Esta legitimação era buscada junto àquelas parcelas da sociedade que congregavam os mesmos ideais. $\mathrm{O}$ combate ao comunismo foi a primeira bandeira erguida pelos militares; atendendo ao clamor da Nação, a intervenção nada mais seria do que a salvação contra o perigo que se aproximava ${ }^{7}$.

Outro elemento que foi essencial neste processo foi a manutenção, num primeiro momento, das instituições pré-1964. Os militares não romperam com a antiga ordem quando tomaram o poder, mantendo a Constituição de 1946 e até mesmo as eleições marcadas para $1965 \mathrm{sem}$ qualquer alteração. Isto foi fundamental para transparecer a imagem das ações como sendo de salvaguarda do país e, assim que normalizados os distúrbios, a ordem seria reestabelecida ${ }^{8}$. Obviamente, o "retorno aos quartéis" não ocorreu como o imaginado.

Relativo às instituições pré-golpe, principalmente o Congresso Nacional e os legislativos estaduais e municipais, é importante ressaltar que a manutenção das eleições para as suas composições colaboraram diretamente para a criação de uma imagem de permanência

6 BIZ, Osvaldo; PETERSEN, Aurea Terezinha Tomatis (Org.) Sessante e quatro: para não esquecer. Porto Alegre: Literalis, 2004, p. 66.

7 BIZ; PETERSEN, op. cit., p 67.

8 BIZ; PETERSEN, op. cit., p 67. 


\section{R E V I S TA A N G E L U N O V U S}

da democracia durante o período ditatorial, mesmo após a elaboração e outorga de uma nova constituição, em 1967. Esta democracia foi norteada por uma perspectiva particular de liberdade, em que o governo, aqui visto como o Poder Executivo, desempenhava um papel de organizador da participação eleitoral, excluindo aqueles indivíduos que não congregavam com os valores essenciais da sociedade que queria se criar.

O governo militar passou, portanto, a intervir no sistema político-partidário, depurando-o a sua maneira. Como consequência do avanço dos partidos oposicionistas nas eleições para os governos dos estados de Minas Gerais e Guanabara, em 1965, o presidente Castelo Branco edita o Ato Institucional n.o 2, em outubro daquele ano, extinguindo os partidos políticos. Além disso, foram instituídas regras mais rígidas para a criação de novas siglas, o que ocasionou o surgimento de somente duas agremiações: a Aliança Renovadora Nacional, alinhada ao Regime Militar, e o Movimento Democrático Brasileiro, oposição institucionalmente consentida ${ }^{10}$. Governantes legalmente eleitos foram depostos e as eleições para governador de estado passaram a ser indiretas, realizadas através das Assembleias Legislativas ".

Instaurado o bipartidarismo, as antigas forças políticas reorganizaram-se, constituindo os dois partidos surgidos em 1965, havendo, portanto, uma modificação na lógica de até então. No estado do Rio Grande do Sul, no entanto, esta realidade se nota diferente. Enquanto que nos outros estados o pluripartidarismo era a base da república populista, naquele estado a polarização política já se fazia presente muito antes do golpe. Ou seja, quando o bipartidarismo aportou, encontrou um terreno favorável para sua absorçãa ${ }^{12}$.

Esta polarização existente desde 1945 na política regional gaúcha dava-se em torno do apoio ou oposição ao trabalhismo. Os polos PTB/anti-PTB alternavam-se no poder ${ }^{13}$. Diante

9 REZENDE, Maria José de. A ditadura militar no Brasil: repressão e pretensão de legitimidade: 1964-1984. Londrina: UEL, 20oI, p. IO5.

CHIAVENATO, Júlio José. O golpe de 64 e a ditadura militar. São Paulo: Moderna, 1994, p. 76.

II REIS FILHO, Daniel Aarão. Ditadura militar, esquerdas e sociedade. 3. ed. Rio de Janeiro: Zahar, 2005 , p. 44 .

I2 NOLL, Maria Izabel; TRINDADE, Hélgio. Estatísticas eleitorais do Rio Grande da América do Sul: I823/2002. Porto Alegre: UFRGS, 2004, p.65.

Para apresentar, resumidamente, a dinâmica partidária regional, entre 1945 e 1965 , apropriamo-nos dos ensinamentos de Hélgio Trindade e Maria Izabel Noll (1995: I45): "As análises sobre o período multipartidário no Rio Grande do Sul tem enfatizado que a polarização partidária não se manifestava apenas nas eleiçóes para o Governo do Estado e o Senado, mas reproduziam-se nas coligações locais, criando uma competição bipartidária de fato por trás do sistema formalmente multipartidário. A polaridade PTB/anti-PTB representava o perfil dominante do período, com tendência a aglutinar mais partidos na medida em que a força do PTB se expandia.” A alternância desses polos pode ser evidenciada, como referido, nos resultados eleitorais nos pleitos para governador, no mesmo período, contando com vitórias de ambos os lados: 1947 - Walter Só Jobim, eleito pelo PSD; 1950 - Ernesto Dornelles, eleito pelo PTB; 1954 Ildo Meneghetti, eleito pelo PSD; 1958 - Leonel Brizola, eleito pelo PTB; e 1962 - Ildo Meneghetti, eleito 
RAMOS FILHO, André Luiz dos Santos (...) USP - Ano IX, n. I4, p. II7-I38, 2018 disso, a imposição do bipartidarismo somente se sobrepôs a uma realidade que existia previamente.

O bloco trabalhista, formado pelo Partido Trabalhista Brasileiro (PTB), o Partido Social Progressista (PSP) e uma parcela do Partido da Representação Popular (PRP), tornouse a base do MDB. A ARENA, por sua vez, constituiu-se do bloco conservador-liberal, composto pelo Partido Social Democrático (PSD), a União Democrática Nacional (UDN), o Partido Libertador (PL), o Partido Democrata Cristão (PDC) e, ainda que parcialmente, o Partido da Representação Popular (PRP) ${ }^{14}$.

Apesar das siglas serem claramente identificáveis quando da adesão aos dois novos partidos criados, elas não respondem uma dúvida importante: quem aderiu à ARENA, no Rio Grande do Sul, quando da sua formação? Poucos autores citam nomes, como se não fosse relevante personificar quais os políticos gaúchos apoiaram o golpe e, mais além, constituíramse como a base de apoio civil aos militares.

Ao fazer isto, procuramos, também, evidenciar o perfil do partido governista. Nomes como Ildo Meneghetti, governador eleito do Estado em 1964, Walter Perachi Barcelos, Euclides Triches, Sinval Guazzelli e Amaral de Souza, são os mais lembrados, principalmente por terem chefiado o Executivo estadual durante os anos do regime. Ainda sim, milhares de outros políticos nos municípios, funcionários públicos civis e militares, proprietários de terras, empresários, entre outros, compunham o corpo anônimo que aderiram, direta ou indiretamente, ao partido. As votações que a ARENA recebeu, durante o período de 1966 e 1974, demonstram o seu aporte perante a sociedade gaúcha. Lúcia Grinberg, ainda que não escreva diretamente sobre o Rio Grande do Sul, caracteriza muito bem os componentes da ARENA:

(...) a Arena formou-se a partir de uma extensa rede de políticos organizados em cada município, provenientes tanto da UDN quanto do PSD, cuja organização em todo o território nacional era um dos seus valiosos capitais políticos. A perspectiva da Arena como herdeira do PSD reafirma a sua condição de partido ligado ao Estado, ao governo, e mostra que a Arena foi um partido da continuidade, daqueles que estavam ligados ao governo há décadas [grifo nosso] Is.

pelo PSD. Fonte: TRIBUNAL REGIONAL ELEITORAL DO RIO GRANDE DO SUL, Eleições Gerais Anteriores a 1990. Disponível em < www.tre-rs.jus.br> Acesso em Io fev. 2017.

NOLL, Maria Izabel; TRINDADE, Hélgio (Coord.) Estatisticas eleitorais comparativas do Rio Grande do Sul: 1945-1994. Porto Alegre: Ed. da Universidade / UFRGS, 1995, p. 145.

Is GRINBERG, Lucia. Uma memória política sobre a Arena: dos "revolucionários de primeira hora” ao "partido do sim, senhor”. In: REIS FILHO, Daniel Aarão; RIDENTI, Marcelo; MOTTA, Rodrigo Patto Sá. (Org.) O golpe e a ditadura militar: quarenta anos depois (1964-2004). Bauru: EDUSC, 2004, p. I45. 


\section{R E V I S TA A N G E L U N O V U S}

Esta identificação da ARENA com o adesismo ${ }^{16}$ justifica, parcialmente, a expressiva quantidade de votos que o partido recebeu durante o período do bipartidarismo. Certamente, enquanto agremiação ligada à máquina estatal, a formação de um cenário eleitoral favorável lhe era menos dificultosa. Porém, não se pode negar o caráter de ato político do eleitorado quando a escolha recaía sobre aqueles nomes associados à ARENA.

\section{A disputa ao Senado}

O mês de fevereiro de 1966 marcou o fim das eleições para o cargo de governador de estado, conforme determinava o texto do Ato Institucional n.o 3. Foram mantidos, no entanto, os pleitos diretos para o legislativo, em todas as esferas: federal, estadual e municipal. Consequentemente, a disputa pelas cadeiras no Senado adquiriu maior visibilidade, visto que era a única eleição majoritária regional que restara.

O primeiro pleito sob a égide do bipartidarismo, marcado para is de novembro daquele mesmo ano, renovou um terço da composição do Senado Federal. Utilizando-se das novas regras estabelecidas pelo voto vinculado, a ARENA lançou três candidatos: o já senador Guido Mondin, Mário Mondino e Synval Guazzelli. O MDB, por sua vez, apresentou candidato único, o senhor Siegfried Heuser. A contabilização dos votos, a partir da imposição da vinculação destes com o partido, funcionava com uma espécie de legenda. Todos os votos dos três candidatos da ARENA eram somados para, só então, serem confrontados com os recebidos pelo candidato do $\mathrm{MDB}$. $\mathrm{O}$ vencedor seria determinado pela votação nominal recebida, desde que seu partido tenha angariado mais votos na soma total ${ }^{17}$.

Além da peculiaridade da soma dos votos dos candidatos, de acordo com o partido, a eleição de 1966 também contou com outra novidade: a adoção de cédula única para a disputa ao Senado. Até 1965, a legislação eleitoral não previa a confecção das cédulas pela Justiça Eleitoral, ou seja, o eleitor depositava na urna, ou uma cédula fornecida pelo candidato/partido, ou uma cédula confeccionada por ele mesmo ${ }^{18}$. Com a edição do Código

O termo adesismo deve ser tomado, neste caso, como a expressão da adaptação, ou subordinação, dos grupos políticos a uma dada conjuntura, visando a permanência daqueles no poder. Esta vinculação com o aparato estatal é fundamental para a manutenção das relações clientelistas entre políticos e eleitorado, como bem coloca Lúcia Grinberg, op. cit., p. I43.

I7 Informações sobre o sistema de contabilização dos votos ao Senado eram veiculadas na imprensa durante o período da campanha eleitoral, como pode ser visto em: CORREIO DO POVO, Porto Alegre, 02/11/1966 p. 7 .

I8 O Código Eleitoral de 1950, Lei I.I64, de 24 de julho de I950, em seu artigo 87, quando da disciplinação do ato de votar expressa: "o eleitor colocará a cédula ou cédulas de sua escolha na sobrecarta recebida do presidente da mesa” [grifo nosso]. 
RAMOS FILHO, André Luiz dos Santos (...) USP - Ano IX, n. I4, p. II7-I38, 2018

Eleitoral de 1965, através da Lei 4.737, de is de julho daquele ano, a Justiça Eleitoral deveria fornecer as cédulas, que passariam a ter um padrão determinado. Todavia, para o pleito de 1966, ocorreu a outorga, pelo Executivo, de um Ato Complementar, o de número 20, no qual ficou estabelecido que, excepcionalmente, nas eleições diretas pelo sistema proporcional daquele ano, somente seria obrigatório o uso da cédula oficial de votação nas capitais dos Estados e nas cidades de população igual ou superior a cem mil habitantes.

Diante disso, havia dois modelos de cédulas oficiais. Um primeiro, que continha todos os cargos em disputa (Senado, Câmara Federal e Assembleia Legislativa), que deveria ser utilizado somente nas cidades de Porto Alegre, Santa Maria, Canoas e Pelotas; e um segundo modelo, contendo somente os candidatos ao Senado, que seria distribuído aos demais municípios. Nestes últimos, a votação para os cargos proporcionais - Câmara Federal e Assembleia Legislativa - seria realizada com cédulas não fornecidas pela Justiça Eleitoral.

A campanha eleitoral foi envolta de um clima de tensão. Como bem coloca Daniel Aarão Reis Filho sobre esta conjuntura no país: "Mas nem com muita boa vontade se poderia dizer que foram eleições livres e democráticas, cercadas que foram por ameaças e intimidações de toda a espécie” ${ }^{19}$. Não era intenção de o governo proporcionar igualdade de manifestação política aos envolvidos com as campanhas. A própria imprensa noticiava a ingerência que órgãos estaduais, ligados à segurança pública, realizavam sobre os atos de campanha, como fica explicitado em matéria veiculada no jornal Correio do Povo, no dia 2 de novembro daquele ano. Nessa, foi noticiado que o Tribunal Superior Eleitoral havia solicitado ao Tribunal Regional Eleitoral que representasse perante o governador do Estado, Ildo Meneghetti, para que não houvesse interferência na fiscalização da propaganda eleitoral, atividade de competência exclusiva daquele órgão ${ }^{20}$.

De outro lado, as ameaças de cassações políticas tornavam as candidaturas do MDB possíveis alvos de processos arbitrários. O próprio candidato ao Senado, Siegfreid Heuser, tivera o nome cogitado como provável cassado, o que gerou extrema revolta por parte dos correlegionários medebistas. Organizados, os candidatos do MDB à Câmara Federal e à Assembleia consideravam, inclusive, a alternativa de retirada coletiva das candidaturas, antes mesmo do pleito, como forma de protesto se algo de anormal ocorresse à Heuser ${ }^{21}$.

Do ponto de vista da corrida eleitoral em si, nota-se que o palanque da ARENA no Rio Grande do Sul, contou, fortemente, com a colaboração dos governantes militares e, também, com outros políticos que já exerciam cargos na administração federal e estadual. Os

19 44 .

20

2I
CORREIO DO POVO, Porto Alegre, 2 nov. 1966, p. II.

CORREIO DO POVO, Porto Alegre, 5 nov. 1966, p. 07. 


\section{R E V I S T A A N G E L S N O V U S}

discursos, de uma forma geral, convergem para a ideia de que o resultado da eleição seria uma demonstração que o rompimento imposto em 1964 foi aceito pela população. Além disso, fica clara a intenção de reforçar a premissa de que seria um erro retornar ao modelo anterior ao golpe, devido aos perigos que o país e, consequentemente, o Rio Grande do Sul, estavam correndo. O presidente eleito, Marechal Costa e Silva, pronunciou-se nesse sentido, em visita ao Estado, para um encontro na sede do partido governista, ocorrido no dia 7 de novembro daquele ano:

(...) O Rio Grande precisa integrar-se na Federação Brasileira. Por incrível que pareça o Rio Grande, com homens do Rio Grande no governo, foi por muito tempo marginalizado. E porque? Porque aqueles homens, que de gaúchos só tinham o fato de haverem nascido aqui, serviam-se do Rio Grande mas não serviam ao Rio Grande. E nós precisamos, os amigos da ARENA, os amigos da Revolução que salvou o Brasil, e salvou o Rio Grande, dizer ao povo do Rio Grande que jamais voltaremos à situação anterior. (...) O governo que vem aí, o Governo da República, que eu representarei em breve, precisa do Rio Grande e precisa que o povo vote na ARENA para que esse governo tenha um parlamento sólido, coeso e unido ao seu lado. (...) Porque o que é certo e evidente (e eu reafirmo, afirmo e confirmo): jamais voltaremos ao passado. [grifo nosso] ${ }^{22}$

O apoio à ARENA não vinha somente do lado governamental. Grupos sociais influentes manifestavam-se publicamente como apoiadores dos candidatos do partido, como pode ser analisado em um evento que foi promovido em homenagem ao então senador e presidente do partido no estado, Daniel Krieger. Um banquete foi oferecido no dia II de novembro, poucos dias antes do pleito, no qual se fizeram presentes algumas personalidades influentes da economia gaúcha, como coloca a matéria veiculada no Correio do Povo, no dia I2 do mesmo mês: "a propósito do banquete oferecido, na noite de quinta-feira ao senador Daniel Krieger, porta-voz da ARENA gaúcha destacou, ontem, o grande e expressivo número de representantes das classes produtoras do Estado presentes ao restaurante do Palácio do Comércio" ${ }^{23}$.

As manifestações pró-ARENA oriundas tanto dos quadros governamentais, quanto dos representantes dos principais setores da economia, refletiam uma tendência relevante de que os candidatos detinham a preferência de grande parcela da sociedade gaúcha, o que ficou comprovado no resultado do pleito. 
RAMOS FILHO, André Luiz dos Santos (...) USP - Ano IX, n. I4, p. II7-I38, 2018

TABELA r: ELEIÇÃO PARA O SENADO FEDERAL NO RS EM 1966

\begin{tabular}{lllll}
\hline Candidato & Partido & Votos & Percentual (\%) & Resultado \\
\hline SIEGFRIED HEUSER & MDB & 638.140 & 40,43 & \\
\hline GUIDO MONDIN & ARENA & $322.90 \mathrm{I}$ & 20,46 & ELEITO \\
\hline SYNVAL GUAZZELI & ARENA & 206.917 & I3,II & \\
\hline MÁRIO MONDINO & ARENA & I42.662 & 9,04 & \\
\hline VOTOS EM BRANCO & & II5.809 & 7,34 & \\
\hline VOTOS NULOS & & I52.086 & 9,63 & \\
\hline
\end{tabular}

Fonte: TRIBUNAL REGIONAL ELEITORAL DO RIO GRANDE DO SUL, Eleições Gerais Anteriores a 1990. Disponível em: www.tre-rs.jus.br. Acesso em 25 jan. 2014.

Apesar de Guido Mondin ter recebido, nominalmente, menos votos que o candidato do MDB, a soma das votações de Synval Guazzeli e Mário Mondino, garantiram a eleição daquele, e a sua permanência no Senado Federal como representante do estado. Ainda que a diferença de votação entre os partidos tenha sido pequena ( 34.487 votos em um universo de I. 578.515 , pouco mais de $2 \%$, portanto), esta se configura como uma ruptura na tendência evolutiva que a fase pré-bipartidarismo possuía, o que demonstra uma tomada de posição política de parcela do eleitorado, frente ao contexto da Ditadura Militar.

A vitória da ARENA, em 1966, deu-se pelo sucesso de seus candidatos no interior do estado, certamente. Dos municípios com maior número de eleitores, somente Caxias do Sul e Pelotas apresentaram resultados ${ }^{24}$ favoráveis ao partido governista, contando com $45,54 \%$ e 40,21\% dos votos, respectivamente. Nos municípios menores o domínio da ARENA foi mais visível, atingindo, em alguns casos, patamares percentuais acima de 60 pontos, como foi o caso das cidades de Anta Gorda (6o,38\%), Paraí (69,49\%) e São Martinho (66,57\%).

Não era somente a disputa por uma cadeira no Senado Federal que estava em jogo na eleição de 1966. O êxito da ARENA, naquele contexto de transição, referendou, ainda que indiretamente, o rompimento imposto em 1964. Este processo se assevera e, quatro anos depois, um novo pleito majoritário se desenrolaria, mas agora em um novo momento: o Regime Militar estava plenamente implantado e suas diretrizes políticas e econômicas geravam profundos efeitos no país.

24 Os resultados eleitorais de 1966, por município, foram consultados em: NOLL, Maria Izabel; TRINDADE, Hélgio (Coord.) Estatisticas eleitorais comparativas do Rio Grande do Sul: 1945-1994. Porto Alegre: Ed. da Universidade / UFRGS, I995. 


\section{R E V I S T A A N G E L S N O V U S}

\section{I. 1970 e o Crescimento da ARENA}

Os anos finais da década de 1960 foram palco do aprofundamento dos dois principais pilares do governo militar: a repressão político-ideológica e o desenvolvimentismo econômico. A edição do Ato Institucional n.ำ 5, no final do ano de 1968, oficializou a postura da chamada linha-dura. Os poderes extraordinários dados ao Executivo para reprimir os subversivos e censurar a imprensa, ou qualquer outra fonte de manifestação pública, acabaram por tornar as ações oposicionistas praticamente impossíveis ${ }^{25}$.

No campo econômico, o planejamento estatal gerava frutos e o Milagre Brasileiro era saudado como a grande conquista daqueles anos. O Estado do Rio Grande do Sul também se beneficiava deste desenvolvimento, assim como vivia o encrudescimento da repressão, como afirma Wassermann sobre o contexto do início da década de 1970:

durante este período, a economia do Rio Grande do Sul acompanhou a euforia do país, devido ao sucesso da lavoura de soja. A repressão aos movimentos sociais, estudantis e populares se manteve nas dependências do DOPS em Porto Alegre, e a censura aos meios de comunicação se intensificou neste período $^{26}$.

O governo não tardou em se aproveitar politicamente do crescimento econômico do país. O sucesso na economia passou a integrar o discurso de legitimação da Ditadura, a partir da subida ao poder do General Médici. Nas palavras de Biz e Petersen:

com a instalação do governo Médici, ocorre uma movimentação no sentido de criar novos instrumentos legitimadores do regime autoritário. A ideia de segurança nacional passou então a ser associada sistematicamente à ideia de desenvolvimentismo. O discurso de combate à subversão e ao comunismo foi substituído por um discurso otimista que colocava toda sua ênfase no Brasil Grande, no Brasil-potência e no "Milagre Brasileiro"27.

É neste contexto que se deu o pleito para o Senado Federal, em i97o. Diferentemente de 1966, em 1970 estavam em jogo duas cadeiras na câmara alta. A ARENA lançou como candidatos Daniel Krieger e Tarso Dutra. O primeiro buscava a reeleição, pois

CHIAVENATO, Júlio José. O golpe de 64 e a ditadura militar. São Paulo: Moderna, 1994, p. 76-77.

WASSERMANN, Claudia. Rio Grande do Sul, "celeiro do Brasil". In: PADROS, Enrique Serra et al. $A$ ditadura de segurança nacional no Rio Grande do Sul (I964-1985): história e memória. 2. ed. Porto Alegre: Corag, 20Io. Iv., p. 66.

BIZ, Osvaldo; PETERSEN, Aurea Terezinha Tomatis (Org.) Sessante e quatro: para não esquecer. Porto Alegre: Literalis, 2004, p. 69-70. 
RAMOS FILHO, André Luiz dos Santos (...) USP - Ano IX, n. I4, p. II7-I38, 2018 havia sido eleito senador em 1962. Tarso Dutra, por sua vez, era deputado federal. Ambos gozavam de grande influência no cenário regional e nacional após o golpe de 1964.

Pelo lado do MDB, temos a candidatura de Geraldo Brochado da Rocha e Paulo Brossard. Este, oriundo das fileiras do extinto Partido Libertador, era advogado de renome no estado. Além disso, fora eleito deputado federal em 1966 pela oposição, o que sacramentou a sua mudança de posicionamento político, visto que pertencia ao grupo que apoiara o golpe. Esta peculiaridade na trajetória do candidato Brossard foi amplamente usada pela ARENA durante o período da campanha.

Com relação à propaganda eleitoral, nota-se uma mudança no perfil das manifestações dos partidos e candidatos, quando comparados ao pleito anterior. As publicações na imprensa adquiriram um caráter muito mais visual, utilizando fotos dos candidatos ao Senado e do próprio presidente Médici, no caso dos candidatos arenistas, além de recursos de imagens de logotipos. Frases de efeito passaram a ser corriqueiras junto aos informes das propostas dos postulantes ao cargo. A ARENA atrelou, por óbvio, a imagem dos seus candidatos à euforia ocasionada pelo milagre econômico.

Um exemplo elucidativo do novo tipo de propaganda usada pela ARENA foi uma publicação de página inteira no jornal Correio do Povo do dia Io de novembro daquele ano, em que, em letras garrafais, lia-se a seguinte frase: "Primeiro passo no programa de integração social”. Acompanhando a chamada, havia o texto:

\footnotetext{
o governo deu a você participação na riqueza nacional. Ajude o governo a lhe dar mais benefícios. Lembre-se que todo o poder está em suas mãos. Seu poder é o VOTO. Dê um passo a frente no dia is de novembro, elegendo os candidatos da ARENA. Vote ARENA - o passo a frente. ${ }^{28}$
}

Fica nítida a estratégia do partido em vincular seus candidatos ao panorama positivo que vivia, ou se pensava viver, a economia brasileira. O slogan "Vote ARENA - o passo a frente", foi adotado em diversas peças publicitárias na imprensa escrita, principalmente relacionado aos postulantes às cadeiras do Senado. No dia 8 de novembro, observa-se outra intervenção de uma página, apresentando as fotografias de Tarso Dutra e Daniel Krieger com o título: "Estes homens querem continuar trabalhando. Dê um passo a frente com eles". Logo abaixo constava o texto:

Escolas, estradas, pontes, saúde, casas, crédito e estímulo à produção... muito do que hoje o Rio Grande tem, foi conquistado com o trabalho destes homens. E eles querem continuar trabalhando, para ajudar a construir o Rio Grande. Com o seu voto você pode levá-los ao Senado da República. 


\section{R E V I S TA A N G E L U N O V U S}

Lembre-se que cada voto nos candidatos da ARENA é uma pedra a mais na construção do grande Rio Grande. No dia is de novembro dê um passo a frente, lado a lado com estes homens. Vote ARENA - o passo a frente ${ }^{29}$.

Esse discurso da propaganda arenista possuía um objetivo bem claro: construir uma relação entre todos os supostos avanços alcançados no Rio Grande do Sul após a instalação do Regime de 1964, e os candidatos do partido, Tarso Dutra e Daniel Krieger, postulantes ao Senado. O anúncio atribui, personificadamente, as obras e políticas públicas realizadas no estado ao trabalho daqueles, visto que faziam parte do governo desde o início.

A quantidade e o foco da publicidade que o partido governista utilizou durante a campanha foram objeto de destaque até mesmo na oposição, que criticou a diferença de recursos entre as duas agremiações para expor as suas propostas e, também, o uso eleitoreiro dos órgãos públicos estaduais e municipais. Nesse sentido se manifestou Pedro Simon, então deputado estadual, em sessão plenária da Assembleia Legislativa que foi transcrita em matéria do dia 7 de novembro, no jornal Correio do Povo $^{30}$. Este tipo de denúncia demonstrava o quanto eram díspares os meios disponíveis para a utilização dos dois partidos na corrida eleitoral. A oposição, neste sentido, enfrentava muito mais dificuldades, financeiras e políticas, de se fazer presente na mesma proporção que a ARENA.

Durante a campanha, também foi possível observar uma postura mais combativa dos candidatos, quando confrontados através da própria imprensa, ou no horário eleitoral gratuito. Esse aspecto não ocorreu com a mesma frequência em 1966. Nota-se que os discursos proferidos eram rebatidos, publicamente, a fim de gerar polêmica entre as partes, geralmente baseado em posturas e entendimentos que o candidato possuía no passado. Essas manifestações eram colocadas em práticas por grupos de apoiadores das campanhas e eram chamados de "apedido". O candidato Paulo Brossard, por sua trajetória política, foi alvo constante destas publicações, como se vê no dia ıo de novembro, no jornal Correio do Povo:

Telegrama ao Deputado Paulo Brossard de Souza Pinto.

Estarrecido e indignado ouvi teu pronunciamento na noite de terça-feira. Me foi difícil acreditar estar ouvindo o Deputado Paulo Brossard, pois poderia esperar ouvir de tua voz o mesmo linguajar e métodos utilizados pelo adversário que nós, juntos, ontem combatíamos. Métodos, processos políticos e administrativos que felizmente foram sepultados por uma revolução. Bendita revolução que além de estar transformando o país com extraordinárias obras em todos os setores, a começar por medidas efetivas e reais em favor das classes menos favorecidas, tem o grande e incomensurável mérito 
RAMOS FILHO, André Luiz dos Santos (...) USP - Ano IX, n. I4, p. II7-I38, 2018 de devolver ao povo aquilo que já não mais possuíamos que é a fé e a esperança nos destinos da pátria $(\ldots)^{31}$

O tom do manifesto evidencia a intenção de demonstrar uma suposta incoerência no comportamento do candidato do MDB que, em tempos passados, ou seja, antes do golpe, era contra os mesmos argumentos que agora utilizava para enfrentar o grupo político que detinha o poder. Além disso, reforça os efeitos positivos da revolução, entre eles, o "sepultamento" das práticas políticas que seriam nocivas ao país.

Nesses mesmos moldes, temos outra manifestação, apedido, mandada publicar em data próxima ao pleito, em que são relembradas as opiniões de Paulo Brossard sobre temas importantes do passado recente; opinióes estas, retiradas de discursos na Assembleia Legislativa do Estado, no desempenho de mandato de deputado estadual, que versavam sobre o governo Vargas, o governo João Goulart, o golpe de 1964, entre outros:

Ontem... E hoje...

Opiniões do candidato Paulo Brossard de Souza Pinto Sobre:

Governo Getúlio Vargas:

'...foi, realmente, Ministra da ditadura, da ditadura fascista que Vargas instaurou no Brasil. Pelo que se vê Sr. Presidente e Srs. Deputados curou-se do mal do fascismo, curou-se do mal do Estado Novo que os pupilos do Estado Novo querem ressuscitar no Brasil' (20/03/1964)

Governo João Goulart:

'em dois anos e meio o Governo Goulart destruiu tudo - a moeda que caiu a níveis jamais sonhados e imaginados' (30/03/1964)

'...destruiu também, a confiança no futuro e a própria alegria de viver. Este é o saldo de dois anos e meio de Governo de Goulart' (30/03/1964)

'...até quando a imensa maioria do povo brasileiro vai assistir a ação predatória, a ação destruidora de uma minoria fanatizada e fanática que dá o colorido e domina o Governo do Sr. Goulart' (30/03/1964)

Revolução de 1964 :

'...uma revolução eclodida no centro do País e logo generalizada, estourando em diversos pontos do território nacional, deu por terra com o Governo que, ainda há alguns dias, movia guerra contra a Constituição e contra o Brasil' (02/04/1964)

'...especialmente depois da revolução que sepultou um regime corrompido até a alma e, além de corrompido, que na sua irresponsabilidade abria as portas da Pátria à penetração do imperialismo soviético, especialmente depois da revolução que há de marcar, queira Deus, uma época nova na história do Brasil novo...' (28/04/1964) [grifo nosso $]^{32}$

CORREIO DO POVO, Porto Alegre, I4 nov. I970, p. o9. 


\section{R E V I S T A A N G E L U S N O V U S}

Referindo-nos a mesma nota impressa, o autor, ao final, coloca:

Estas opiniões demonstram que a "política" do candidato ao Senado, Sr. Paulo Brossard de Souza Pinto, tem servido apenas a sua própria carreira, as conveniências de momento (...)

O Rio Grande saberá escolher os seus representantes no Senado pela sua autenticidade e coerência, repelindo os individualistas, que em nada contribuem para a construção de uma Pátria melhor. ${ }^{33}$

Fica claro o objetivo do autor ao enumerar os posicionamentos de Brossard. Ao colocar as opiniões do candidato ao longo do tempo, principalmente a partir da conjuntura do governo João Goulart, a nota demonstra bem como se desenvolveu o apoiamento dos atos de 1964. Obviamente, quando afrontadas com o fato de aquele ser postulante ao cargo de senador pelo $\mathrm{MDB}$, seis anos depois, não há como negar a contradição de opiniões, ainda que não se trate do mesmo contexto político-partidário.

Os ataques provinham, ainda, de antigos aliados que, com a instalação do novo regime e a extinção dos partidos tradicionais, reagruparam-se em torno da ARENA, como pode ser visto em anúncio feito na véspera do dia da eleição, dia I4 de novembro, no jornal Correio do Povo:

\footnotetext{
Apoio dos Pasqualinistas.

Em face de declarações feitas, através da rádio e TV, pelo ilustre líder do MDB, Deputado Pedro Simon, com referência a apoio prestado por pasqualinistas às candidaturas de Salgado Martins a deputado federal e Tarso Dutra e Daniel Krieger ao Senado, julgo-me no dever de reafirmar que os pasqualinistas gaúchos devem mesmo votar nestes candidatos, pois foram os ilustres homens públicos Tarso Dutra e Daniel Krieger os que encaminharam, na Câmara dos Deputados e no Senado Federal, um projeto, transformado em Lei, concedendo uma pensão vitalícia ao nosso saudoso chefe Alberto Pasqualini, quando o mesmo ficou completamente abandonado por muitos de seus amigos companheiros $(\ldots)^{34}$
}

Embora aparentemente contraditório um alinhamento de pasqualinistas com os candidatos da ARENA ao senado, isto pode ser compreendido como resultado do movimento de absorção de alguns grupos políticos pela base de apoio do Governo Militar. Como uma espécie de moeda de troca, estes grupos colaboravam no período eleitoral.

Os severos embates entre os apoiadores dos candidatos, acirrando os debates entre os partidos, acabaram por favorecer a estratégia da ARENA que, catapultada pelos bons 
RAMOS FILHO, André Luiz dos Santos (...) USP - Ano IX, n. I4, p. II7-I38, 2018 resultados da política econômica daquele momento, fez convergir para si a maior parte do eleitorado, como podemos ver pelo resultado do pleito do dia is de novembro de 1970.

TABELA 2: ELEIÇÃO PARA O SENADO FEDERAL NO RS EM 1970

\begin{tabular}{lllll}
\hline Candidato & Partido & Votos & Percentual (\%) & Resultado \\
\hline TARSO DUTRA & ARENA & $929.46 \mathrm{I}$ & 22,88 & ELEITO \\
\hline DANIEL KRIEGER & ARENA & 864.505 & 21,28 & ELEITO \\
\hline PAULO BROSSARD & MDB & 833.630 & 20,52 & \\
\hline GERALDO BROCHADO & MDB & 809.296 & 19,92 & \\
DA ROSA & & & & \\
\hline VOTOS EM BRANCO & & 491.422 & I2,IO & \\
\hline VOTOS NULOS & & 133.750 & 3,29 &
\end{tabular}

Fonte: TRIBUNAL REGIONAL ELEITORAL DO RIO GRANDE DO SUL, Eleiçōes Gerais Anteriores a 1990. Disponível em: www.tre-rs.jus.br. Acesso em 25 jan. 2014.

Tarso Dutra foi o grande vitorioso nas eleições de 1970. Senador mais votado, atingindo uma diferença de 96.165 votos para o mais votado candidato da oposição, o deputado Paulo Brossard. Com relação à Geraldo Brochado da Rosa, essa diferença é ainda maior: 120.165 votos. Daniel Krieger, o segundo senador eleitor, obteve uma votação menor que seu colega de agremiação, mas com uma diferença considerável do segundo candidato da oposição: 55.209 votos.

Ao se observar as votações alcançadas em sua totalidade, verifica-se que houve um crescimento eleitoral da ARENA com relação ao pleito de 1966. Naquela oportunidade, a diferença entre os números obtidos por cada partido foi menor do que a presente em 1970, ficando em torno de $2 \%$. Na eleição em tela, esta diferença aumentou para 3,72\%, que apesar de pequena, representava, na prática, mais de 150.000 votos. Ou seja, o partido governista expandiu o seu eleitorado.

Outro aspecto relevante foi a redução do percentual de votos nulos, de 9,63\% em 1966, para 3,29\% em 1970. Isto demonstra um maior engajamento por parte dos eleitores, que optaram por nominar seus escolhidos. O aumento do percentual de votos em branco, por sua vez, de 7,34\% em 1966, para 12,10\% em 1970, é consequência natural da possibilidade de voto em dois candidatos. Aquele eleitor que sufragava em somente um candidato acabava, automaticamente, votando em branco para o segundo nome, daí a elevação do índice desse tipo de voto.

Ao analisarmos o resultado do pleito sob a perspectiva geográfica, verificaremos que a vitória da ARENA se construiu a partir da elevação de sua dominação nos municípios de pequeno porte, que passa a atingir 40,8\% dos casos. Somado a isso, temos a redução brusca do 


\section{R E V I S TA A N G E U S N O V U S}

domínio da oposição, que passa a ser 5,7\% dos municípios, além do aumento do percentual de cidades em que não há uma dominação explícita. Em suma, a ARENA, em 197o, passa a ser o partido majoritário no interior e, nos casos onde isso não é possível, ela neutraliza, significativamente, a ação do $\mathrm{MDB}$, visto que o percentual de municípios sem dominação cresce para $53,5 \% 35$.

Certamente, a eleição de 1970 marcou o ápice da manifestação eleitoral a favor do regime implantado em 1964, representado pelos candidatos da ARENA. No entanto, o desenrolar da década colocaria em cheque o modelo capitaneado pelos militares.

\subsection{O início do fim: 1974 e o avanço da oposição}

Ao término do governo Médici, o projeto econômico da Ditadura começava a demonstrar os primeiros sinais de esgotamento. A inflação reapareceu na vida dos brasileiros, e a recessão ressurgia atingindo os empregos e a capacidade do governo em saldar os seus compromissos internos e externos. Em março de 1974, subia ao poder o general Geisel, trazendo consigo a missão da transição controlada à democracia ${ }^{36}$.

Diante do fato de que o crescimento da economia não atingia os patamares dos primeiros anos da década, o discurso do Milagre Brasileiro, como instrumento de legitimação dos militares, perdeu sentido. Assim, era preciso criar um novo foco. Como bem coloca Biz e Petersen:

o discurso, que no início da década de setenta, deixara de chamar atenção ao perigo da ameaça comunista, para concentrar-se no Brasil Grande, no Milagre Brasileiro, passou a ter outra tônica - a da construção da democracia. Foi adotada a estratégia de fazer certas concessões que objetivavam, em primeiro lugar, diminuir a tensão que tendia a acumular-se na sociedade e, em segundo lugar, manter um grau aceitável de legitimação do governo militar ${ }^{37}$.

É nesse contexto que o pleito para o Senado Federal se desenrolaria, em 1974. A disputa pela cadeira gaúcha na câmara alta foi protagonizada por Paulo Brossard, candidato do MDB e que já havia concorrido ao cargo em I97o, e Nestor Jost, candidato da ARENA,

35 NOLL, Maria Izabel; TRINDADE, Hélgio. Estatísticas eleitorais do Rio Grande da América do Sul: I823/2002. Porto Alegre: UFRGS, 2004, p. I04.

36 REIS FILHO, Daniel Aarão. Ditadura e Sociedade: as reconstruções da memória. In: REIS FILHO, Daniel Aarão; RIDENTI, Marcelo; MOTTA, Rodrigo Patto Sá. (Org.) O golpe e a ditadura militar: quarenta anos depois (1964-2004). Bauru: EDUSC, 2004, p.44.

37 BIZ, Osvaldo; PETERSEN, Aurea Terezinha Tomatis (Org.) Sessante e quatro: para não esquecer. Porto Alegre: Literalis, 2004, 72. 
RAMOS FILHO, André Luiz dos Santos (...) USP - Ano IX, n. I4, p. II7-I38, 2018 que objetivava ser o sucessor de Guido Mondin, então senador pelo Rio Grande do Sul, que se afastaria da vida pública ao término de seu mandato. Jost era funcionário público, presidente do Banco do Brasil entre os anos de 1967 e 1974, e gozava de muito prestígio perante os setores públicos estaduais e federais no estado.

A campanha na imprensa, por sua vez, deu-se em um clima de intensa confiança de ambos os lados. Algumas manifestações de Nestor Jost demonstravam profunda segurança que o pleito seria vencido pela ARENA, como podemos ver em matéria do Io de novembro de 1974, com o título "Jost renova confiança no eleitorado de Porto Alegre":

Durante um jantar com integrantes do Clube dos Repórteres Políticos, o sr. Nestor Jost disse que confia no eleitorado de Porto Alegre (...) Assegurou que ganhará porque tem um partido com mais votos que o MDB. E como o eleitorado segue sempre o mesmo rumo, o fato deverá se repetir ${ }^{8}$.

Interessante ressaltar a confiança na manutenção da intenção de voto do eleitorado. A expressão "segue sempre o mesmo rumo" demonstra bem a ideia de que se pensava existir uma maneira única de pensar dos eleitores, ou seja, se antes apoiavam o partido governista não havia por que pensar que poderiam alterar seus votos.

Como de costume, a máquina estatal se fez presente no palanque do candidato arenista, através de diversos colaboradores, nas mais diferentes cearas. No dia 6 de novembro, foi veiculada reportagem no jornal Correio do Povo relatando o encontro de Nestor Jost com os prefeitos da Grande Porto Alegre, no qual compareceram o prefeito da capital, Thompson Flores, Ariosto Jaeger e o ex-ministro do governo Médici, Pratini de Moraes. Este fez apologia aberta a Jost, como podemos ver por trecho de seu discurso:

Meus srs. precisamos ter gente como Nestor Jost atuando no Senado Federal, porque tenho certeza de que a sua atuação não só vai ajudar a resolver os problemas das áreas metropolitanas, que certamente não se vão consolidar sem os grandes volumes de recursos para planejamento e realização de obras fundamentais ${ }^{39}$.

Mais uma vez a campanha arenista vislumbrava contar com o apoio dos políticos locais, principalmente quando coloca a questão da necessidade da vitória do seu candidato para que fosse garantida a solução dos problemas que os centros urbanos enfrentavam. A questão dos recursos para obras e outras realizações também era usada como elemento de persuasão.

38 CORREIO DO POVO, Porto Alegre, Io nov. 1974, p. 07.

39 CORREIO DO POVO, Porto Alegre, 6 nov. 1974, p. 09. 


\section{R E V I S T A A N G E L U S N O V U S}

Os membros do governo Geisel também auxiliaram na campanha da ARENA para o Senado. Arnaldo Pietro, então Ministro do Trabalho, atuou, com autorização da presidência, em prol do fortalecimento da candidatura de Jost, como pode ser observado em matéria do jornal Correio do Povo de 9 de novembro (CORREIO DO POVO, 9/II/1974:7):

O ministro Arnaldo Pietro garantiu, hoje, uma vitória total da ARENA no Rio Grande do Sul onde vem atuando através de constantes viagens de conotação política. (...) o titular do Trabalho pode consolidar sua posição política no Rio Grande do Sul, afirmando, inclusive, que o candidato Nestor Jost está com seu lugar garantido no Senado ${ }^{40}$.

A atuação de ministros de estado, como foi o caso de Arnaldo Pietro, estava inserida na concepção já largamente utilizada de que o governo deveria fazer tudo aquilo que estivesse ao seu alcance para garantir a vitória dos seus candidatos. Não existia nenhuma intenção de se esconder tal situação.

Nem só de manifestações de confiança se caracterizou a campanha, no entanto. Explorando a biografia política de Paulo Brossard, alguns discursos de repúdio foram publicados, objetivando acender antigas rusgas que aquele possuía com os trabalhistas, antes da implantação do bipartidarismo. Ainda que unidos sob a mesma bandeira, o MDB, dissidentes do Partido Libertador e membros do Partido Trabalhista Brasileiro mantinham alguns ressentimentos, como pode ser visto em uma nota apedido, de autoria de Danilo Groff, em que este, trabalhista convicto, repudia a orientação da oposição em torno da candidatura de Brossard:

\footnotetext{
Minha vida pública sempre esteve ligada ao Partido Trabalhista Brasileiro e seus legítimos ideais (...) Com todo este ideal sadio e honesto, só poderia ver com repulsa o ato dos atuais dirigentes que indicam ao sufrágio dos trabalhistas, o nome repelente de Paulo Brossard que era exatamente o homem que mais atacava o trabalhismo e que mais calúnias, difamações e injúrias, assacava contra os líderes do $\mathrm{PTB}$ (...) Somente é candidato do MDB porque não conseguiu tal posição no partido do Governo, mas continua sendo o inimigo dos trabalhistas ${ }^{41}$
}

A nota acima demonstra bem como a oposição não era um grupo homogêneo, longe disso. O bipartidarismo impôs aproximações que antes dele não seriam toleradas. Este é o caso de Paulo Brossard, icônico membro do Partido Libertador. Esta característica auxiliou o governo, visto que a oposição não contava com a mesma coesão interna que o partido oficial da Ditadura. 
RAMOS FILHO, André Luiz dos Santos (...) USP - Ano IX, n. I4, p. II7-I38, 2018

Mesmo com todo o otimismo situacionista, e a tentativa de desqualificação da candidatura da oposição, a ARENA sofreu o seu mais profundo baque eleitoral desde a implantação do bipartidarismo, em 1965. O resultado das urnas demonstrava um cenário diferente daquele imaginado pelos governistas.

TABELA 3: ELEIÇÃO PARA O SENADO FEDERAL NO RS EM 1974

\begin{tabular}{lllll}
\hline Candidato & Partido & Votos & Percentual (\%) & Resultado \\
\hline PAULO BROSSARD & MDB & I.383.288 & 53,62 & ELEITO \\
\hline NESTOR JOST & MDB & 897.803 & 34,80 & \\
\hline VOTOS EM BRANCO & & 195.303 & 7,57 & \\
\hline VOTOS NULOS & & I03.380 & 4,01 &
\end{tabular}

Fonte: TRIBUNAL REGIONAL ELEITORAL DO RIO GRANDE DO SUL, Eleiçôes Gerais Anteriores a 1990. Disponível em: www.tre-rs.jus.br. Acesso em 25 jan. 2014.

A retumbante vitória do MDB surpreendera o mais pessimista dos arenistas ${ }^{42}$. A diferença entre a votação obtida por Nestor Jost e Paulo Brossard, 485.485 votos, significou mais do que uma simples derrota eleitoral. A ARENA viu reduzida a sua força em todos os municípios com mais de 30.000 eleitores ${ }^{43}$; até mesmo Caxias do Sul e Pelotas, cidades que em 1966 e 1970 detinham percentuais favoráveis ao partido, apresentaram, em 1974, respectivamente, $32,20 \%$ e $27,80 \%$.

O Rio Grande do Sul seguia a tendência do restante do país: em 1974, 59,3\% do eleitorado pendeu para o MDB, ficando a ARENA com 4I\% dos votos ${ }^{44}$. Neste sentido, 1974 foi um ano emblemático para o Regime Militar. Nas palavras de Daniel Arão Reis Filho "os anos seguintes assistiriam ao progressivo deslocamento da sociedade brasileira, e de suas elites políticas e econômicas, no rumo da defesa do restabelecimento das instituições democráticas”45. A Ditadura Militar havia sido atingida em um de seus mais preciosos pontos de sustentação: a pretensa legitimação eleitoral. A partir de então, a manutenção de um regime de exceção encontrava cada vez menos apoiadores.

42 RODEGHERO, Carla Simone. Regime militar e oposição. In: BOEIRA, Nelson; GOLIN, Tau (Coord.) História Geral do Rio Grande do Sul. Passo Fundo: Méritos, 2007. 4v., p. IO2.

43 Os resultados eleitorais de 1974, por município, foram consultados em: NOLL, Maria Izabel; TRINDADE, Hélgio (Coord.) Estatísticas eleitorais comparativas do Rio Grande do Sul: 1945-1994. Porto Alegre: Ed. da Universidade / UFRGS, I995. CHIAVENATO, Júlio José. O golpe de 64 e a ditadura militar. São Paulo: Moderna, 1994, p. 80.

45 REIS FILHO, Daniel Aarão. Ditadura e Sociedade: as reconstruções da memória. In: REIS FILHO, Daniel Aarão; RIDENTI, Marcelo; MOTTA, Rodrigo Patto Sá. (Org.) O golpe e a ditadura militar: quarenta anos depois (1964-2004). Bauru: EDUSC, 2004, p. 44. 


\section{R E V I S TA A N G E U S N O V U S}

\section{Considerações Finais}

A implantação da Ditadura Militar no Brasil não pode ser compreendida somente como um golpe que, em 31 de março de 1964, alterou a ordem institucional do país. O processo de legitimação do projeto do novo regime foi construído ao longo dos anos que se seguiram a deposição de João Goulart. A manutenção de eleições e a instituição do bipartidarismo, em 1965, são elementos que auxiliaram neste objetivo.

No Rio Grande do Sul, diferentemente de outros estados, a bipolarização ARENA - MDB encontrou um cenário favorável para se desenvolver. Rapidamente, as estruturas políticas tradicionais se acomodaram nos novos partidos e a dinâmica eleitoral assumiu novas características.

Entre 1966, primeira eleição sob o sistema bipartidário, e 1970, o partido governista arregimentou o maior número de apoiadores nas urnas. Nesses pleitos, a ARENA atingiu votações, para o Senado Federal, de 42,61\% e 44,16\% respectivamente, vencendo-os. No entanto, a historiografia, de um modo geral, não estabelece um vínculo de importância entre estas eleições e a aceitação da Ditadura pelos gaúchos, acabando por deter-se, somente, no pleito de 1974, em que o MDB saiu vitorioso.

Essa leitura parcial parte de uma perspectiva, em que são ressaltados aqueles acontecimentos que demonstravam o repúdio ao Regime Militar. As votações da ARENA são apresentadas como resultado das manobras do próprio Estado, quase que ilegítimas, como podemos depreender do que afirmam Marcello Baquero e Jussara Reis Prá:

\footnotetext{
indubitavelmente, as estratégias adotadas pelo regime autoritário, entre as quais a reformulação do sistema de partidos, primeiro com o bipartidarismo e, mais tarde, como retorno ao multipartidarismo, buscavam evitar o avanço das forças partidárias com apelo popular. Inicialmente, eliminaram a possibilidade do PTB se tornar majoritário na principal coligação da "democracia populista" (PSD-PTB), finalmente, numa tentativa de dar sobrevida ao regime militar, procuraram tornar o antigo PSD viável eleitoralmente por intermédio dos partidos conservadores (ARENA e PDS $)^{46}$.
}

Outra justificativa para as derrotas da oposição até 1974 reside na elevação da importância dos votos brancos e nulos. Neste sentido, Hélgio Trindade e Maria Isabel Noll destacam:

46 BAQUERO, Marcello; PRÁ, Jussara Reis. A democracia brasileira e a cultura politica no Rio Grande do Sul. Porto Alegre: UFRGS, 2007, p. 84. 
RAMOS FILHO, André Luiz dos Santos (...) USP - Ano IX, n. I4, p. II7-138, 2018

Nas eleições de 1974, o MDB consegue mobilizar o eleitorado de oposição ao regime através da candidatura ao Senado de Paulo Brossard. O clima da campanha, marcado pela defesa da democracia, denúncia do regime autoritário e crítica liberal à ausência de direitos políticos, canalizou o voto da população urbana identificada como o MDB e certamente uma parcela significativa do eleitorado do antigo PTB que preferira, até então, optar por anular o voto 47.

Tal abordagem, ainda que estatisticamente possível se fossem somados todos os votos nulos aos candidatos da oposição, acaba por desmerecer o sufrágio daqueles que compareceram às urnas e nominaram os seus candidatos. Além disso, a preferência pela anulação, na ótica de Trindade e Noll, não leva em conta a inconformidade do eleitor com os próprios candidatos da oposição.

Ao contrário do que afirmam os autores citados anteriormente, a ARENA possuía um eleitorado próprio, o que pode ser demonstrado com a manutenção dos percentuais no patamar acima de 40\% nos anos de 1966 e 1970 . Se comparados com o resultado do pleito de 1974, o pior do período, não há um decréscimo acentuado, no caso, persistindo aquele em $34,8 \%$. Diante disso, a estabilidade do eleitorado do partido governista, somado à característica peculiar da polarização política do estado, vai ao encontro da ideia de que o Regime Militar encontrou significativo apoio em parcela da sociedade gaúcha.

Não se nega, todavia, que existam mais elementos relevantes para a compreensão da dinâmica eleitoral do período, principalmente no tocante à estruturação dos partidos e sua atuação nos municípios. É evidente que, numa conjuntura de regime de exceção, com utilização, em larga escala, de restrições de direitos e sistemas repressivos, deve-se levar em conta a disparidade entre as condições das agremiações em promover o debate e a campanha propriamente dita.

Ainda assim, os dados apresentados por Hélgio Trindade e Maria Izabel Noll (2002: IOI-IO3), no que tange à evolução das dominações eleitorais locais, cobrem grande parte dos municípios do Rio Grande do Sul, demonstrando que, pelo menos estatisticamente, tanto ARENA, quanto MDB, possuíam penetração nas cidades, obtendo melhores, ou piores, resultados de acordo com o perfil do eleitorado.

Quando analisada a votação final de uma eleição, necessita-se, também, efetuar um esforço de compreensão do processo do pleito em si: a campanha eleitoral, a organização dos esforços, os discursos, os apoios, são atos de pessoas que, mergulhadas nos acontecimentos em tempo real, tomam posição, defendendo ideias. Se a historiografia defende que até o voto nulo é um ato político, como já referido na leitura das estatísticas do período bipartidário, o I823/2002. Porto Alegre: UFRGS, 2004, p. 96. 


\section{R E V I S TA A N G L U S N O V U S}

voto num candidato que tenha clara vinculação não pode ser encarado como de menor valor, ou resultado simples de manobras estratégicas do governo.

Por se tratar de tema pouco explorado, o jogo eleitoral durante o período do bipartidarismo acaba por levantar muito mais questionamentos do que respostas. Não se tem a pretensão de esgotar o debate, mas propor possibilidades. Uma delas é o estudo dos resultados eleitorais daquela conjuntura, visando desmistificar a tradicional imagem de que o Regime Militar era um governo "só de militares"; muito antes pelo contrário, foi vital a existência de um corpo de civis que davam suporte ao projeto autoritário, capitaneado pelas forças armadas, mas engendrado pelas elites políticas e econômicas. 